OPEN ACCESS

Edited by:

Sara Invitto,

University of Salento, Italy

Reviewed by:

Sue Morris

Dana-Farber Cancer Institute,

United States

Katie Moraes de Almondes, Federal University of Rio Grande do

Norte, Brazi

*Correspondence

Yoshitake Takebayashi ytake2@fmu.ac.jp

tPresent address:

Yoko Matsuda,

Cognitive Behavioral Therapy and

Research Institute, Musashino

University, Koto-ku, Japan

Specialty section:

This article was submitted to Public Mental Health, a section of the journal

Frontiers in Psychiatry

Received: 03 December 2020 Accepted: 12 May 2021 Published: 04 June 2021

Citation:

Matsuda Y, Takebayashi Y, Nakajima S and lto M (2021) Managing Grief of

Bereaved Families During the COVID-19 Pandemic in Japan

Front. Psychiatry 12:637237. doi: 10.3389/fpsyt.2021.637237

\section{Managing Grief of Bereaved Families During the COVID-19 Pandemic in Japan}

\author{
Yoko Matsuda $^{1 \dagger}$, Yoshitake Takebayashi ${ }^{1,2 \star}$, Satomi Nakajima ${ }^{3}$ and Masaya Ito ${ }^{1}$ \\ ${ }^{1}$ National Center of Cognitive-Behavior Therapy and Research, National Center of Neurology and Psychiatry, Kodaira, Japan, \\ ${ }^{2}$ Department Health Risk Communication, School of Medicine, Fukushima Medical University, Fukushima, Japan, \\ ${ }^{3}$ Department of Human Sciences, Faculty of Human Sciences, Musashino University, Koto-ku, Japan
}

This commentary discussed the psychological issues related to bereavement in the wake of the COVID-19 pandemic. Specifically, we addressed two aspects in the context of Japanese culture. The first relates to the psychological distress of members of the bereaved family who could not visit their loved ones who had COVID-19 before or after their death. The second relates to the bereavement experience of those who were unable to be with their loved ones when the end came, even though they did not have COVID-19, because of restrictions on visiting hospitals. We seek to focus on the need for a support system for bereaved families to help them through the grieving process, and discuss end-of-life care in such circumstances, and in the post-COVID-19 era, as in current day Japan.

\section{Keywords: COVID-19, prolonged grief, ambiguous loss, mourning process, bereavement}

\section{INTRODUCTION}

The number of deaths worldwide due to the COVID-19 pandemic has exceeded 3 million as of April 20, 2021 (1). In this pandemic, the grief response may become more complex and prolonged, leading to psychological problems among people. During the same period, the pandemic caused 9,629 deaths in Japan, a $2 \%$ mortality rate (1). Thus, the number of COVID-19-related deaths has been relatively lower in Japan than in the Western countries, where the infection has exploded (2). As the number of deaths due to the pandemic increases, there is growing focus on the suffering of the bereaved families and their support systems in the wake of the COVID-19 pandemic. Pre and post-face-to-face family contact with loved ones is limited in in order to prevent infection (3). The suddenness and unpredictability of bereavement due to COVID-19 makes it challenging to establish advance care planning, a key component of effective terminal care (4). Bereavement due to COVID-19 infection may also interfere with the adaptive mourning process in terms of disruption of social norms, rituals, and mourning practices for death, as seen during past epidemics of infectious diseases (5). Because of these peculiarities, there is concern that bereavement due to coronavirus infections may increase psychological risks, such as complicated grief and depression $(5,6)$. For this reason, safer funeral practices have been explored in infectious disease pandemic disasters through the modification of funeral rites and the introduction of traditional ritual techniques specific to each culture $(6,7)$.

In the early stages of the pandemic, public awareness regarding COVID-19 deaths was low because there was no rapid increase in the number of deaths in Japan. However, public awareness increased considerably following the mass media broadcasts of the deaths of two celebrities from COVID-19-a popular comedian and a famous actress-in March and April 2020, respectively. 
Around the same time, there were infections among funeral workers, which raised public concern about conducting funerals in these difficult times. It became apparent that bereavement during the COVID-19 pandemic was different from that caused by other types of death in Japan. We addressed two issues related to bereavement. First, family members of persons succumbing to COVID-19 were not allowed to bid goodbye to the deceased before death or see them face-to-face even after death. Second, the impact on end-of-life care and bereavement due to restrictions on visits to hospitalized patients, which had significant ramifications given the fact that a majority of people die in hospitals in Japan (8). We shall discuss efforts to address these issues in Japan.

\section{POTENTIAL PSYCHOLOGICAL CONCERN REGARDING BEREAVEMENT DUE TO COVID-19}

In early April 2020, during the initial stages of the pandemic, a statement regarding its psychological impact was released by the Chairman of the Disaster Preparedness and Disaster Response Committee of the Japanese Society for Traumatic Stress Studies. The statement pointed out that bereavement due to COVID19 could lead to psychological problems such as prolonged grief and ambiguous loss, one which is without closure or clear understanding of why it occurred (9). In order to prevent the spread of COVID-19 in Japan, it was recommended, in principle, that visiting a person at the end of life with COVID-19 infection should be prohibited (10). Not being present at the death of patients with COVID-19 infection impedes the usual farewell rituals conducted for the deceased by the bereaved. For example, touching the deceased's body helps those bereaved to realize that their loved one has actually died. Not being present at the end of a person's life and not being allowed to touch the body potentially interferes with the mourning process and increases the risk of prolonged grief (9). In the Netherlands it was noted that grief levels were higher among people bereaved due to COVID-19 than those who had lost loved ones due to natural causes (11). Traumatic bereavement is more likely to occur when the death of a loved one is sudden or unnatural, such as when a loved one's body is damaged (12). It is accompanied by regret, anger, and guilt over death (For example, could the end have been prevented? Is the loved one suffering? Was death or dying unjust?) (12). Traumatic bereavement is a risk factor for PTSD and depression, as well as prolonged and complicated grief (13). These symptoms after bereavement often co-occur and share common features, but many epidemiological studies support their distinctiveness $(14,15)$. Since bereavement due to COVID-19 shares the common feature of traumatic bereavement (6), systematic psychosocial support is needed. Psychological therapies, such as cognitive-behavioral therapy, optimized for each symptom, have been shown to improve PTSD, grief, and depression after bereavement $(16,17)$.

Although Japan has yet to report any empirical studies on grief after bereavement due to COVID-19, considering its cultural practices regarding funerals, it is reasonable to expect increased rates of prolonged grief. In Japan, it is customary to hold a funeral that is widely attended by family members, locals, or business partners. Such bereavement ceremonies are essential to facilitate the grieving process of the bereaved by allowing them to share their feelings and memories of the deceased. Traditional Japanese funeral ceremonies include sharing meals and alcohol with all the people who attend. However, most funerals have now been restricted in Japan, following instances of people becoming infected with COVID-19 after attending funerals. Being in close physical proximity with friends or others may produce feel-good hormones such as oxytocin, dopamine, and serotonin (18). When they are not physically present to say goodbye and grieve with a loved one, they may be more likely to experience a sense of ambiguous loss (18). An ambiguous loss is an indefinite loss that persists without resolution or closure, such as when a loved one is missing (e.g., kidnapped or swept away by a tsunami and never found) or physically present but psychologically absent (e.g., the former personality is still intact due to dementia) (19). Ambiguous loss differs from ordinary bereavement in that there is no definitive information or finality (19).

In Japan, guidelines regarding COVID-19 patients have been in place right from the beginning of the pandemic. For example, the number of visits to critically ill patients should be limited. Existing restrictions relate to both end-of-life care and contact with the body after death. However, there is the need to take care of family feelings at each stage, which highlights the usefulness of communication through social networking services and online tools in the COVID-19 Nursing Practice Guide for Critically Ill Patients, Version 1 (published in April 2020) (20). In response to such recommendations, efforts at the grassroots level are underway to encourage communication between patients and their families through online communication tools such as videophones. For example, a physician has launched a crowdfunding campaign to purchase tablets in hospitals to facilitate online communication between critically infected patients and their families. He reached his goal in just half a day (21), and by the end of the campaign, he had raised more than five times his goal of more than 16 million yen, enabling distribution of the tablets to approximately 80 facilities (22). Similar efforts-making videoconferencing possible in end-oflife care settings, when patients cannot see their families faceto-face because of the pandemic (23)-are expected to alleviate patients' suffering in a way that medical personnel by themselves cannot. There is also a growing focus on comforting patients in their dying days, with families asking medical personnel to show the patients their favorite pictures and play their favorite music (24).

From the perspective of preventing infection during transportation and cremating the bodies of those who have succumbed to COVID-19, the Japan Medical Association's Implementation Manual (6th edition) (25) requires that crematorium workers and mourners do not touch the body. Under these circumstances, to arrange the farewell ceremony close to the conventional one, flowers and photographs are placed on top of the coffin (which usually mourners set inside the coffin). In case there are restrictions on the number of people who can be present at the funeral, the cremation service provider 
can take pictures of the deceased before the funeral and show them to the family later. The family could also ask the service provider to place photographs, flowers, and other items related to the deceased on the coffin. Such acts at the funeral ceremony perhaps reflect the bereaved family members' sentiments that they are not leaving their loved ones alone at the time of their death. In addition, there is a custom of wiping and cleansing the body and applying makeup on the face after death (so-called angel care), which nurses generally perform when patients die in Japan (26). However, Version 2 of the COVID-19 Nursing Practice Guide for Critically Ill Patients published in July 2020 points out the importance of family members' participation in angel care in terms of grief care (26). The guideline recommends explaining the risk of infection to family members. If they still wish to participate in angel care, one recommendation is that they take the same preventive measures as do the medical personnel like wearing protective clothing, and touching a safe body area where they are not exposed to bodily fluids. Continuous efforts are needed to make mourning rituals safer with technology, and changes in funeral practices acceptable in each local culture (19).

\section{THE IMPACT OF RESTRICTED END-OF-LIFE CARE VISITS FOR NON-COVID-19 INPATIENTS}

Japan has been a super-aged society since 2007. In 2019, 28.4\% of the population were 65 years and above and $4.7 \%$ were 85 years or older (27). In the 1950 s, more than $80 \%$ of people died at home in Japan (28). In 2017 , more than $80 \%$ of patients died in hospitals or institutions (8), despite nearly $70 \%$ of them wanting to die at home (29). Fewer people die at home because of the increasing trend toward nuclear families, which has led to a decline in family relationships (28). Many older relatives are moved into homes for the elderly because it may be a burden on family members and others who care for them (29). It is necessary to improve home medical care in present-day Japan to achieve end-of-life care at home, but only $5 \%$ of all medical institutions could support it in 2014 (8). For these reasons, many patients choose to receive endof-life care for diseases other than COVID-19 in a medical facility or palliative care. However, many hospitals now restrict visits to non-COVID-19 inpatients-a necessary and natural measureto prevent nosocomial infections (infections caused by pathogens in the hospital). There is a concern that these measures will result in a situation where terminally ill, non-COVID-19 patients, will not be provided with adequate end-of-life care. One of the risk factors for prolonged grief and PTSD after the death of a COVID19 patient is the bereaved family's inability to say goodbye to the deceased. Since family members of non-COVID-19 inpatients have restricted visitation, the same psychopathological risk can be assumed for them (3). In light of the philosophy of palliative care, it is desirable for the psychological health of patients and their families to spend time with each other so that the patients are taken care of at the end of their lives, by their own. Therefore, there has been a move to provide a flexible response so that patients can be involved in end-of-life care while taking measures to prevent infection.

In response to this situation, the Japanese Society for Palliative Medicine has suggested in a pamphlet that families should consider caring for patients at home (30). In one such case, based on a nurse's suggestion, a leukemia patient who was prepared to die in the hospital could go home and spend the next 10 days with his family (31). In some areas, the number of individuals switching to end-of-life care at home has nearly doubled compared to previous years (32). Cases of end-of-life care at home have also been reported in the UK and Portugal $(33,34)$. In Portugal, most families encourage terminally ill patients to stay at home for an extended period (34).

Although, in some cases, family members were unable to visit their hospitalized relatives freely during the COVID-19 pandemic, they asked individuals, called end-of-life caregivers, from some organizations such as hospices, to provide endof-life care for terminally ill patients living alone in Japan (35). Conversely, some physicians involved in palliative care have expressed concern about suggesting end-of-life care at home. It is necessary to consider the situation of families who have difficulties or anxieties about administering end-of-life care at home and seek gentle and heartwarming end-of-life care at hospitals for their loved ones, knowing that they will have to observe all the required measures against infectious diseases during their restricted visits (36). The UK has increased opportunities for bereaved institutional support, including the issuance of guidelines by the NHS to allow only one family member to visit patients who are unlikely to recover or who are days or weeks away from their death (37).

Although end-of-life care has been discussed as an issue for medical care in super-aging Japanese society, COVID-19 could be considered an opportunity to think about dying at home. As a country with one of the highest life expectancy levels, Japan has focused on care for the elderly. It is precisely for this reason that it is expected to lead the world in establishing a system of advanced end-of-life care.

\section{RESPONSE TO BEREAVEMENT DUE TO COVID-19 IN JAPAN: LESSONS LEARNED FROM PAST MAJOR DISASTERS}

Japan experienced an extremely high level of loss in the Great East Japan Earthquake of 2011 (38), which led to the development of academic and public health efforts to deal with grief; these were also deployed during the COVID-19 pandemic. For example, the Japan Disaster Grief Support project established after this earthquake and implemented in May 2020, provided grief-related psychoeducational materials for the bereaved (39). Musashino University, the National Center of Neurology and Psychiatry, and others developed several treatment/prevention programs for prolonged grief, which have been shown to be effective in other countries too, based on empirical evidence. These include complicated grief treatment (40) and its Japanese version, along 
with group cognitive behavioral therapy for the bereaved with the distress of grief less severe than complicated grief (41). Since face-to-face therapy is limited during the COVID-19 pandemic, to provide such services, it would be necessary to devise programs including web-based grief treatment and videoconferencing psychotherapy $(42,43)$. We provide a modified treatment program for patients in whom face-to-face treatment at an institution had to be interrupted as a preventive measure against COVID-19. Even before the COVID-19 pandemic, the U.K. and U.S. had established guidelines and training methods for telepsychological interventions and developed laws; this area has not yet been developed in Japan. In the early stages of the pandemic, some academic volunteers translated these guidelines into Japanese. The infrastructure for telepsychological interventions has been developed; however, its growth is not sufficient to meet the demand. Professionals must work together to ensure that grief support continues without interruption. To ensure that those who need help do not suffer, we must provide more flexible support, including online programs that can be implemented for bereaved families in remote areas, in preparation of the post-Corona era.

\section{REFERENCES}

1. Dong E, Du H, Gardner, L. COVID-19 Dashboard by the Center for Systems Science and Engineering (CSSE) at Johns Hopkins University (JHU). ArcGIS. Johns Hopkins University (2021). Available online at: https://gisanddata.maps.arcgis.com/apps/opsdashboard/index.html\#/ bda7594740fd40299423467b48e9ecf6 (accessed April 20, 2021).

2. Alwan NA, Burgess RA, Ashworth S, Beale R, Bhadelia N, Bogaert, D et al. Scientific consensus on the COVID-19 pandemic: we need to act now. Lancet. (2020) 396:71-2. doi: 10.1016/S0140-6736(20)32153-X

3. Morris SE, Moment A, Thomas JD. Caring for bereaved family members during the COVID-19 pandemic: before and after the death of a patient. J Pain Symptom Manage. (2020) 60:e70-4. doi: 10.1016/j.jpainsymman.2020.05.002

4. Moore KJ, Sampson EL, Kupeli N, Davies N. Supporting families in end-oflife care and bereavement in the COVID-19 era. Int Psychogeriatr. (2020) 32:1245-8. doi: 10.1017/S1041610220000745

5. Mayland CR, Harding AJE, Preston N, Payne S. Supporting adults bereaved through COVID-19: a rapid review of the impact of previous pandemics on grief and bereavement. J Pain Symptom Manage. (2020) 60:e33-9. doi: 10.1016/j.jpainsymman.2020.05.012

6. Carr D, Boerner K, Moorman S. Bereavement in the time of coronavirus: unprecedented challenges demand novel interventions. J Aging Soc Policy. (2020) 32:425-31. doi: 10.1080/08959420.2020.1764320

7. Cardoso ÉAO, Silva BCAD, Santos JHD, Lotério LDS, Accoroni AG, Santos MAD. The effect of suppressing funeral rituals during the COVID-19 pandemic on bereaved families. Rev Lat Am Enfermagem. (2020) 28:e3361. doi: 10.1590/1518-8345.4519.3361

8. Ministry of Health, Labour and Welfare. Survey of attitudes toward medical care in the final stages of life report. Ministry of Health, Labour and Welfare (2018). Available online at: https://www.mhlw.go.jp/toukei/list/saisyuiryo_a. html (accessed November 6, 2020).

9. Kato, H. The Psychological Impact of the COVID-19 Pandemic. Japanese Society of Traumatic Stress Studies. (2020). Available online at: https://www.jstss.org/ ptsd/covid-19/page01.html (accessed November 6, 2020).

10. Japanese Society for Infection Prevention and Control. A guide to dealing with COVID-19 infections in medical institutions ver.3. Japanese Society for Infection Prevention and Control (2020). Available online at: http://www. kankyokansen.org/uploads/uploads/files/jsipc/COVID-19_taioguide3.pdf (accessed November 6, 2020).

\section{DATA AVAILABILITY STATEMENT}

The original contributions presented in the study are included in the article/supplementary material, further inquiries can be directed to the corresponding author/s.

\section{AUTHOR CONTRIBUTIONS}

YM and YT conceived the ideas. YM developed the draft paper. MI and SN verified the draft paper as experts in grief-related research and treatment in Japan and supervised this work. YT encouraged YM to investigate the research or guidelines related to bereavement due to COVID-19 in Japan. All authors have discussed the contents and contributed to the final manuscript.

\section{FUNDING}

This work was supported by JSPS KAKENHI (Grant Number 20H01774).

11. Eismaa MC, Tammingab A, Smid GE, Boelen PA. Acute grief after deaths due to COVID-19, natural causes and unnatural causes: an empirical comparison. J Affect Disord. (2020) 278:54-6. doi: 10.1016/j.jad.2020. 09.049

12. Barlé N, Wortman CB, Latack JA. Traumatic bereavement: basic research and clinical implications. J Psychother Integr. (2020) 27:127. doi: $10.1037 /$ int0000013

13. Kokou-Kpolou CK, Moukouta CS, Masson J, Bernoussi A, Cénat JM, Bacqué MF. Correlates of grief-related disorders and mental health outcomes among adult refugees exposed to trauma and bereavement: a systematic review and future research directions. J Affect Disord. (2020) 267:171-84. doi: 10.1016/j.jad.2020.02.026

14. Malgaroli M, Maccallum F, Bonanno GA. Symptoms of persistent complex bereavement disorder, depression, and PTSD in a conjugally bereaved sample: a network analysis. Psychol Med. (2018) 48:2439-48. doi: 10.1017/S0033291718001769

15. Lenferink LI, Nickerson A, de Keijser J, Smid GE, Boelen PA. Reciprocal associations among symptom levels of disturbed grief, posttraumatic stress, and depression following traumatic loss: a four-wave cross-lagged study. Clin Psychol Sci. (2019) 7:1330-9. doi: 10.1177/2167702619858288

16. Johannsen M, Damholdt MF, Zachariae R, Lundorff M, Farver-Vestergaard I, O'Connor M. Psychological interventions for grief in adults: a systematic review and meta-analysis of randomized controlled trials. J Affect Disord. (2019) 253:69-86. doi: 10.1016/j.jad.2019.04.065

17. Eddinger JR, Hardt MM, Williams JL. Concurrent treatment for PTSD and prolonged grief disorder: review of outcomes for exposureand nonexposure-based treatments. OMEGA-J Death Dying. (2019). doi: 10.1177/0030222819854907

18. Weir Grief K. COVID-19: saying goodbye in the age of physical distancing. American Psychological Association (2020). Available online at: https:// www.apa.org/topics/covid-19/grief-distance (accessed November 6, 2020). doi: 10.1037/e502882020-001

19. Pauline E, Boss JY. Ambiguous loss: a complicated type of grief when loved ones disappear. Bereavement Care. (2014) 33:63-9. doi: 10.1080/02682621.2014.933573

20. Japan Society of Critical Care Nursing. COVID-19 Practical Guide to Critical Care Nursing Ver.1.0. Japan Society of Critical Care Nursing (2020). Available online at: https://www.jaccn.jp/guide/pdf/COVID-19_guide1.Ver1. 0.pdf (accessed November 6, 2020). 
21. Japanese Institute of Medicine. Promoting online visitation in the age of living with COVID-19. Weekly Med J. (2020) 2020:3377. Available online at: https://www.igaku191shoin.co.jp/paperDetail.do?id=PA03377_04 (accessed November 6, 2020).

22. Hirohashi T. Making videoconferencing possible in end-of-life care settings where they cannot see their families during COVID-19 pandemic. (2020). Available online at: https://readyfor.jp/projects/palliative-care (accessed November 6, 2020).

23. Utsuki N. Videoconferencing is a new option for end-of-life care. Nikkei Medical (2020). Available online at: https://medical.nikkeibp.co.jp/leaf/all/ report/t344/202005/565572.html (accessed November 6, 2020).

24. The Japanese Society of Intensive Care Medicine. Care for Loss, Grief and Bereavement during COVID-19 pandemic. The Japanese Society of Intensive Care Medicine (2020). Available online at: http://elnecjcc.hs.med.kyoto-u.ac. jp/data/COVID-19/COVID-19_PART2-3.pdf (accessed November 6, 2020).

25. Japan Medical Association. COVID-19 Infection: Manual for the Transportation, Funeral and Cremation of Bodies Ver.5.0. (2020). Available online at: https://www.jmari.med.or.jp/download/sousaimanual5.pdf (accessed November 6, 2020).

26. Japan Academy of Critical Care Nursing. The Japanese Society of Intensive Care Medicine COVID-19 Critical Care Nursing Practice Guide Ver.2.0. Japan Medical Association. Available online at: https:// www.jsicm.org/news/upload/COVID-19_nursing_guide_v2.pdf (accessed November 6, 2020).

27. Health, Labour and Welfare. White Paper. (2020). Available online at: https:// www.mhlw.go.jp/toukei_hakusho/hakusho/index.html (accessed November 6, 2020).

28. Shimada I. $80 \%$ of people in Japan die in hospital: the reason why "I want to spend my last days at home” doesn't get real. Gento-sha Gold Online (2020). Available online at: https://gentosha-go.com/articles/-/22078 (accessed November 6, 2019).

29. Ministry of Health, Labour and Welfare. End-of-life -reference materials. Available online at: https:/www.mhlw.go.jp/file/05-Shingikai12404000-Hokenkyoku-Iryouka/0000156003.pdf (accessed November 6, 2017).

30. Japanese Society for Palliative Medicine brochure about COVID-19:finished version 2. Available online at: https://www.pref.hiroshima.lg.jp/uploaded/ attachment/396604.pdf (accessed November 6, 2020).

31. Asahi Digital. Some people don't get to see their families at the end of life - Ten days for the 222 patient who complained. (2020). Available online at: https://digital.asahi.com/articles/ASN5967C9N57UTIL03V.html? pn=9 (accessed November 6, 2020).

32. Asahi Digital. Want to see him/her at the end of life: COVID-19, which prevents wishes. 226 Getting double the end-of-life care at home. (2020). Available online at: https://digital.asahi.com/articles/ASN596H4ZN58UTIL03C.html (accessed November 6, 2020).

33. Katz NT, McInerney M, Ravindran G, Gold M. Silent suffering of the dying and their families: impact of COVID-19. Intern Med J. (2021) 51:433-5. doi: 10.1111/imj.15101

34. Carvalheiro AM, Faria C, Semeão I, Martinho SM. Caring for end-of-life patients and their families, during life, and mourning, in the COVID-19 era-the experience of a palliative care team in Portugal. Front Psychiatry. (2021) 12:624665. doi: 10.3389/fpsyt.2021.624665

35. NIKKEI. The scene of their final days which COVID-19 changed: end-of-life care is at home. (2020). Available online at: https://r.ni kkei.com/article/DGKKZO62603760T10C20A8KNTP00?lightid_token=eyJh bGciOiJIUzI1NiIsInR5cCI6IkpXVCJ9.eyJraWppX2lkIjoiREdLS1pPNjI2M DM3NjBUMTBDMjBBOEtOVFAwMCIsImF0bGFzX2lkIjoiZDlzLWxqYjRta C0yYWxsYjVoLWpvYzN6M2ZkZ2t0MzVhb2tuMXN0cXhjaC1za2Q3Z296c F92czE5eXQ5cDBoaSIsImlhdCI6MTU5OTYzNTMzMCwiZXhwIjoxNTk5 NjQyNTMwfQ.F5cPC0jfwc2lr0jN0uqEpofMCd5FmHxpLmGJF90D0uQs=6 (accessed Nobember 6, 2020).

36. Shinjo, T. Hasn't palliative care killed itself by COVID-19? The medical profession has violated 237 the rights of the dead. BUZZFEED Japan (2020). Available online at: https://www.buzzfeed.com/jp/takuyashinjo/covid238 19palliative-care (accessed November 6, 2020).

37. NHS. Guidance for Visitors during the COVID-19 Pandemic Visiting Restrictions: an information guide. (2020). Available online at: https:// www.pat.nhs.uk/downloads/New\%20NCA\%20Leaflets/COVID-19/910 \%20-\%20Guidance\%20for\%20Visitors\%20during\%20the\%20COVID- 19 \%20Pandemic\%20Visiting\%20Restrictions.pdf (accessed April 18, 2021).

38. Ranghieri F, Ishiwatari M, editors. Learning From Megadisasters: Lessons from the Great East Japan Earthquake. The World Bank (2014). doi: 10.1596/978-1-4648-0153-2

39. Japan Disaster Grief Support. Support for the bereaved during COVID-19 pandemic. (2020). Available online at: https://jdgs.jp/wp-content/uploads/ 2020/06/70681bce9d0f5eb3afd733f2af78e47a.pdf (accessed November 6, 2020).

40. Okazaki J, Nakajima S. Practice of complicated grief treatment. Japan J Trauma Stress. (2018) 16:5-10.

41. Kurosawa M, Sasaki S, Ueda M, Nakajima S, Kim Y. Practice of group cognitive behavioral therapy for distress of grief. Japan J Trauma Stress. (2018) 16:17-23.

42. Shirai A, Nakajima S, Wagner B. Cognitive-behavioral therapy for complicated grief using email. Japan J Trauma Stress. (2018) 16:11-6.

43. Boelen PA, Maarten C, Eisma MC, Smid GE, Keijser J, Lenferin L. Remotely delivered cognitive behavior therapy for disturbed grief during the COVID-19 Crisis: challenges and opportunities. J Loss Trauma. (2020) 16:211-9. doi: 10.1080/15325024.2020. 1793547

Conflict of Interest: The authors declare that the research was conducted in the absence of any commercial or financial relationships that could be construed as a potential conflict of interest.

Copyright (C) 2021 Matsuda, Takebayashi, Nakajima and Ito. This is an open-access article distributed under the terms of the Creative Commons Attribution License (CC $B Y)$. The use, distribution or reproduction in other forums is permitted, provided the original author(s) and the copyright owner(s) are credited and that the original publication in this journal is cited, in accordance with accepted academic practice. No use, distribution or reproduction is permitted which does not comply with these terms. 